Military Technical College

Kobry El-Kobbah,

Cairo, Egypt

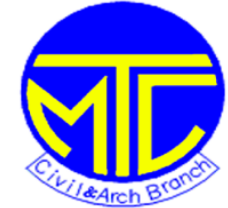

$11^{\text {th }}$ International Conference

on Civil and Architecture

Engineering

ICCAE-11-2016

\title{
Optimum Structural Design of Deep Submarine Pressure hull to
} achieve Minimum Weight

\author{
Elsayed Fathallah ${ }^{1}$, Mahmoud Helal ${ }^{2}$ \\ ${ }^{1}$ Civil Engineering Department, M.T.C. Kobry Elkobba - Cairo, Egypt \\ ${ }^{2}$ Production and Mechanical Design Dept., Faculty of Engineering, Mansoura University, Mansoura, \\ EGYPT
}

\begin{abstract}
The pressure hull is a significant structural component of underwater vehicles, to enable them to withstand environmental loadings such as hydrostatical pressure. Geometric configurations such as hull shape, shell thickness, stiffener layout, and type of construction materials are the key factors influencing the structural performance of pressure hulls. This study aims to maximize the structural efficiency of elliptical deep-submerged pressure hull under hydrostatic pressure. Minimize the buoyancy factor of a submarine pressure hull under hydrostatic pressure was proposed as an objective function to achieve Minimum Weight, with constraints on factors such as general instability, buckling of shell between stiffeners, plate yielding, stiffeners yielding and operating depth. The shell thickness, the radii of the ellipse, the stiffeners offsets and the stiffeners dimensions are selected as design variables. Additionally, a sensitivity analysis is performed to study the influence of the design variables on the structural optimum design, the buoyancy factor, strength and stability. The Optimization results of this study provide a valuable reference for designers of underwater vehicles.
\end{abstract}

Keywords : optimum; submarine; pressure hull; buckling; buoyancy factor. 


\section{Introduction}

Ship and submarine design is a complex and distributed process, and with the development of computer applications in ship and submarine design, optimization plays an important role in this process. Recently, due to the depths of the sea, military research, development and business needs, deep sea submersible research work began to be put on the agenda, and gradually, become a hot spot especially the pressure hull which ensure the safety of divers and a key component of stability which caught the attention of some scholars.

An important element of any submersible is the pressure hull. The pressure hull is the main watertight structural component of a submarine that houses personnel, propulsion machinery, weapons and sensor systems, and other sensitive equipment. Pressure hulls are designed to withstand the hydrostatic load associated with diving to depths usually measured in the hundreds of meters [1].

The pressure hull is the main structure of a deep-diving submersible vehicles and frequently constitutes one-half and more of the total weight of the vehicle [2]. One of the major problems confronted by the designer of deep submersibles is to minimize the weight of the pressure hull, to increase the payload, propulsion velocity of submersible vessels, reduce the cost of submarine construction, and life support for the hull with the lowest weight to buoyancy ratio at a given depth. These improvements can be achieved through the advanced hull concept and efficient material systems [2, 3]. Buoyancy requirement for the weight-sensitive structures can be easily meet by applying a composite material, which has an excellent specific strength and stiffness and therefore can be able to reduce the weight of the structure itself. In addition, the danger of being detected by sonar can be reduced while the resistance to corrosion can be increased because the composite sandwich has excellent sound absorption properties and is stable against the chemical reaction [4]. A submarine designer pointed out that the safety factor of 1.5-2.0 is considered acceptable in most engineering practice [5]. Liang et al. $[6,7]$, optimized the design of filament-wound multilayer sandwich submersible pressure hulls, taking into consideration the shell buckling strength constraint, the angle-ply laminated facing failure strength constraint and the low-density isotropic core yielding. The facings become thicker and the core becomes thinner as the operational depth increases. Graphite/Epoxy is a better choice than Boron/Epoxy and Glass/Epoxy for facings material. Also, Boron/Epoxy is preferred as a facing's material at shallow depths, but Graphite/Epoxy is preferred at extreme depths. Also, the optimal model's weight reduces an average $6.65 \%$ more than the prototype model when a minimum weight design of a submarine pressure hull under hydrostatic pressure was proposed. Guang et al.[8] investigated the optimization of composite cylindrical shell subjected to hydrostatic pressure, using the method of distribution optimization. From the result, the buckling pressure has been greatly improved without changing the shape and the structure of the vehicle. Khairul Alam et al. [9] Presented an efficient evolutionary approach for the preliminary design of Autonomous underwater vehicles (AUVs). The framework is the first of its kind to offer full multidisciplinary design optimization 
functionalities to be considered in the design of AUVs. Pan and Cui [10], established a new safety standard for titanium manned spherical pressure hulls of manned submersible. A structural optimization of the titanium alloy spherical pressure hull of a $4500 \mathrm{~m}$ deep manned submersible was performed and the weight of the hull reduced by about 11\%. Elsayed Fathallah et al. [11-13] optimized a lay-up and composite material system for minimize the buoyancy factor. Also, investigated the multi-objective optimization of composite elliptical submersible pressure hull for minimize the buoyancy factor and maximize buckling load capacity. Panteleev [14], investigated the optimum design of metallic sandwich structures and assured a diminution in its weight of $23 \%$ as compared with the constant thickness plate. Garland [15], presented the design requirements used to construct the pressure hull of a deep submergence vehicle. The results showed that, not only the weight/buoyancy ratio plays an important role in determining the payload of a deep-diving submersible vehicles pressure hull, but also, a higher strength material requires less weight and provides better buoyancy which increasing a higher permitted payload. Alvarez et al. [16], optimized the hull geometry to reduce the total resistance and show that, the hull shape resulting from the optimization process substantially reduces (up to 25\%) the estimated total resistance. Cui et al. [17], performed the structural optimization of a bulk carrier with two conflicting objectives (weight and fatigue) as a case study. A JAVA-based optimization system and ABAQUS were integrated into the optimization framework. Ahn and Ruzzene [18], optimized the tapered and stiffened configurations to enhance the overall stability characteristics of the vehicle, and compared the results with that of plain shells to show the effectiveness of the proposed configurations. Tokugawa [19], the first one observed that the general instability of stiffened cylindrical shell occurs at structural locations between bulkheads or deep frames. Bagheri et al. [20], applied the genetic algorithm method to the multi-objective optimization problem of ring stiffened cylindrical shells. The results showed that, stiffening a cylindrical shell, yields lower structural weight, higher natural frequencies and buckling loads. In addition, the distribution of the stiffeners plays a key role on the magnitudes of the natural frequencies and buckling loads. Jeong and Henry [21], presented an alternative approaches that, can be used to obtain optimal geometric shape, wall thickness, construction material configuration and stiffener layout of a pressure hull. Jen et al. [22, 23], presented the optimal design of a small-scale midget submersible vehicle (MSV) pressure hull with a ring-stiffened cylinder and two hemispherical ends subjected to hydrostatic pressure, and investigated the dynamic responses of a multiple intersecting spheres (MIS) deep-submerged pressure hull subjected to underwater explosion. Ross [24], introduced an alternative design for submarine pressure hull without ring-stiffeners. The shell instability and general instability are resisted by making the pressure hull into a swedged-shaped form. The swedged-shaped hulls are more structurally efficient than conventional ring stiffened equivalent of the same volume and weight. Ross and Little [25], predicted the four lobe buckling mode of a corrugated carbon fiber vessel under external pressure using FE program BCLAM. The failure mode was found experimentally and the predicted buckling pressure was higher than the experimental values, by approximately $20 \%$. The actual buckling pressure was 
expected to be lower than the FE results, because the latter assumes perfect circular geometry. Ross and Popken [26], carried out experimental tests on three tube-stiffened prolate hemi-ellipsoidal domes under external water pressure. The tubes were stuck to the internal surfaces of these three domes, in their flanks. The experimental tests showed that the tubes increased the buckling pressures of these domes, especially in one case, when the tube was subjected to an initial internal pressure. Harris [27] and Ross [28], suggested that the pressure hull should be stiffened by tubes placed longitudinally along it. Also, it may be more desirable to have circumferential tubes. Furthermore, if the tubes are subjected to internal pressure so that the hull is in a state of initial tension, then the buckling resistance of the hull can be even further increased. Wu et al. [29], studied the optimum design of spherical deep-submerged pressure hull, considering the effect of material nonlinearity and proposed formula of non linear stability for spherical thick hulls. Moon et al. [30], investigated the buckling and post buckling behavior of moderately thick walled, filament-wound, carbon epoxy cylinders, subjected to hydrostatic pressure, the analyses were conducted using the finite element program ACOS and predicted that the buckling pressure with 2-23\% deviation from experimental results. The results show that finite element analysis can be used to evaluate the buckling load of moderately thick-walled, filament-wound composite cylinders under external hydrostatic pressure. Maalawi [31], introduced a mathematical approach model for enhancing the buckling stability of composite, thin-walled rings/long cylinders under external pressure using radial material grading concept. The objective is to maximize the critical buckling pressure, while preserving the total structural mass at a constant value, equal to that of a baseline design. The stability limits of the optimized shells have been substantially enhanced as compared with those of the reference or baseline designs. Lee et al. [32], used optimization to increase the design load of composite sandwich cylinders under external hydrostatic pressure. Based on the optimization, as the thickness of the sandwich increases, the buckling load becomes larger than the material failure. Consequently, the optimum point is determined by material failure. The results suggested that both the buckling and the static material failure should be considered in the design of the composite sandwich cylinder. Radha and Rajagopalan [33], demonstrated the analysis of submarine pressure hull structure in which the failure gets governed by inelastic buckling. Three different approaches ('Johnson-Ostenfeld inelastic correction', 'imperfection method' and 'finite element approach') have been employed to investigate the ultimate strength of the ring stiffened submarine pressure hull structure with inelastic buckling modes of failure. The finite element analysis gives almost exact results as the rigorous analysis incorporated all the non-linearities and appropriate boundary conditions. Liang et al. [34], examined the transient dynamic responses of a typical submarine hull subjected to hydrostatic pressure and shock loading. The collapse depth $(700 \mathrm{~m})$ is the maximum diving depth of the submarine pressure hull. The loading condition not only depends on the hydrostatic pressure but also on the shock loading. This paper investigates the optimum design of elliptical deep-submerged pressure hull subjected to hydrostatic pressure using nonlinear finite element analysis software ANSYS.

\section{Pressure Vessel Types}


Fig. 1 shows the different shapes of a submarine pressure hull. Most submarine pressure hulls take the form of a cylinder/cone/dome construction, surrounded by a casing. The purpose of the latter is to improve the hydrodynamic streamlining as shown in Fig. 1a. These structures can fail either through axisymmetric yield or by buckling. Fig. $1 \mathrm{~b}$ shows the spherical pressure hull. A spherical pressure vessel is usually constructed in the form of a thin walled spherical shell with a pressure-tight hatch, to allow access. In the case of mini-submarines, the pressure hull is usually covered with casing to improve hydrodynamic streamlining. Fig. 1c shows the ring-stiffened circular cylinder, blocked by end caps, which is the usual shape of a submarine pressure hull. This is a good structure to resist the effects of external hydrostatic pressure and can making the cylinder longer than a spherical form of the same volume. Usually, in the same displacement pressure shell of various shapes, the spherical pressure hull its weight is small, but the space utilization ratio is small. The process of making the roundness, the accuracy is not easy to control and the production cost is relatively expensive [35]. In this study, a submarine pressure hull in the form of elliptical cylinder as shown in Fig. 2, is considered. Because it has a better space utilization, more efficient than a spherical one for housing large numbers of personnel, good hydrodynamic form better than a spherical form of the same volume, facilitate various instruments layout of the electronic equipment, and also easy to manufacture.

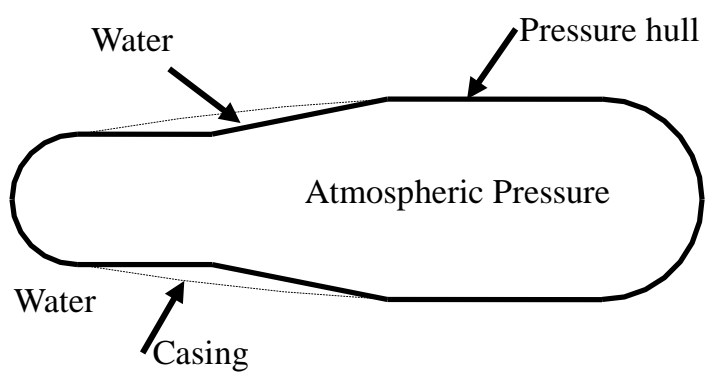

a) Cylinder/cone/dome pressure hull.

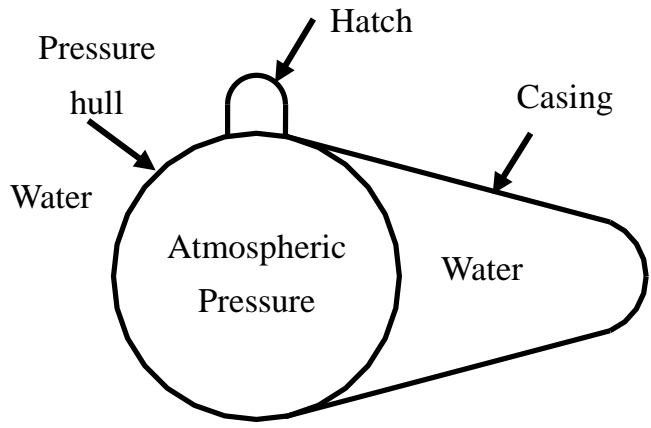

b) The spherical pressure hull.

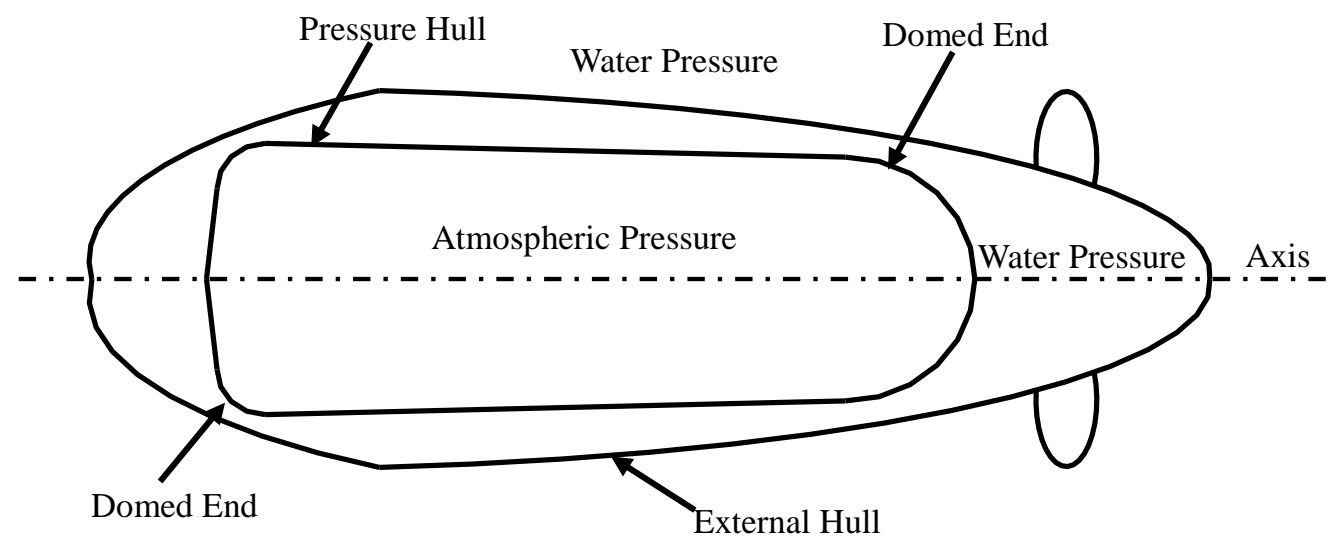


c) Ring-stiffened circular cylinder, blocked by end caps.

Fig. 1Shape of a submarine pressure hull.

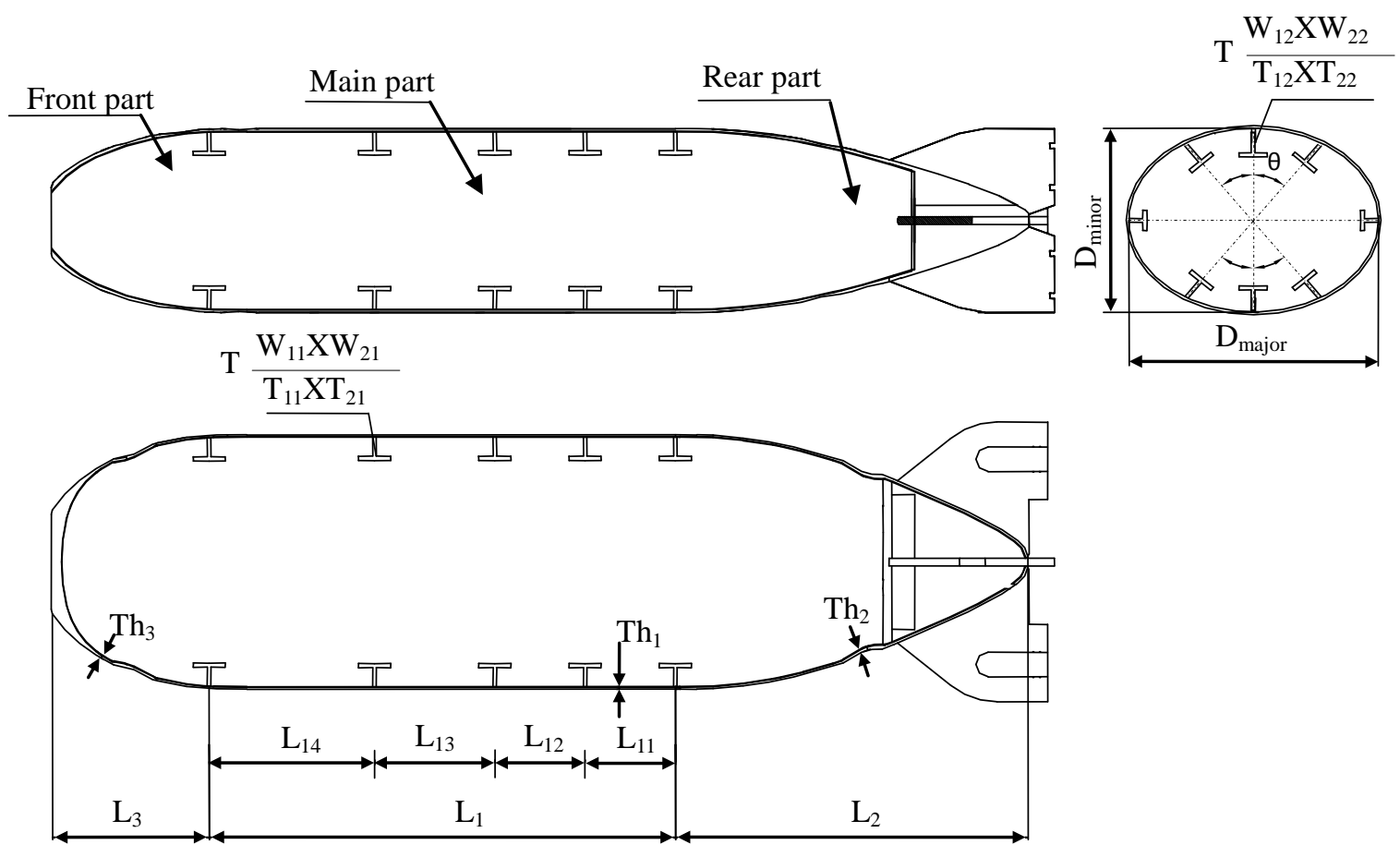

Fig. 2 Geometry of elliptical submersible pressure hulls.

\section{Materials Requirements for Construction}

the materials for underwater pressure vessels must not only be capable of withstanding very high external pressures, but must have other suitable properties that can with stand the environment [35]. Some of the required properties are as good resistance to corrosion, high strength weight ratio (if the wall thickness is too large, the vessel will sink like a stone), good sound absorption qualities, material costs, fabrication properties (can the vessel be manufactured 'easily' in the chosen material), susceptibility to temperature (fire protection) and operating life span of the material.

The main materials for the design of submarine pressure hulls are high strength steels, aluminum alloys, titanium alloys, and composites [35]. In this study, the stiffeners assumed to be constructed from titanium alloys which has high strength weight ratio, and the hull shell assumed to be constructed from HY100 which has high tensile strength, good ductility, notch toughness, atmospheric corrosion resistance and good weldability, as shown in Table 1. The stress-strain diagram for HY100 and Titanium alloys are presented in Fig. 3. 


\section{Structure Optimization}

Design Optimization is a very general automated design technique. Design optimization consists of certain goals (objective functions), a search space (feasible solutions) and a search process (optimization methods). The feasible solutions are the set of all designs characterized by all possible values of the design parameters (design variables). The optimization method searches for the optimal design from all available feasible designs [36-38].

Table 1. Material properties for Steel and Titanium alloy [4, 35, 39]

\begin{tabular}{|c|c|c|c|c|c|}
\hline Material & $\begin{array}{c}\text { Specific } \\
\text { density }\end{array}$ & $\begin{array}{c}\text { Young's } \\
\text { modulus (GPa) }\end{array}$ & $\begin{array}{c}\text { Compressive yield } \\
\text { strength (MPa) }\end{array}$ & $\begin{array}{c}\text { Ultimate } \\
\text { strength (MPa) }\end{array}$ & roisson \\
\hline HY100 & 7.828 & 210 & 690 & 793.5 & 0.29 \\
\hline Titanium & 4.5 & 120 & 827 & 890 & 0.3 \\
\hline
\end{tabular}

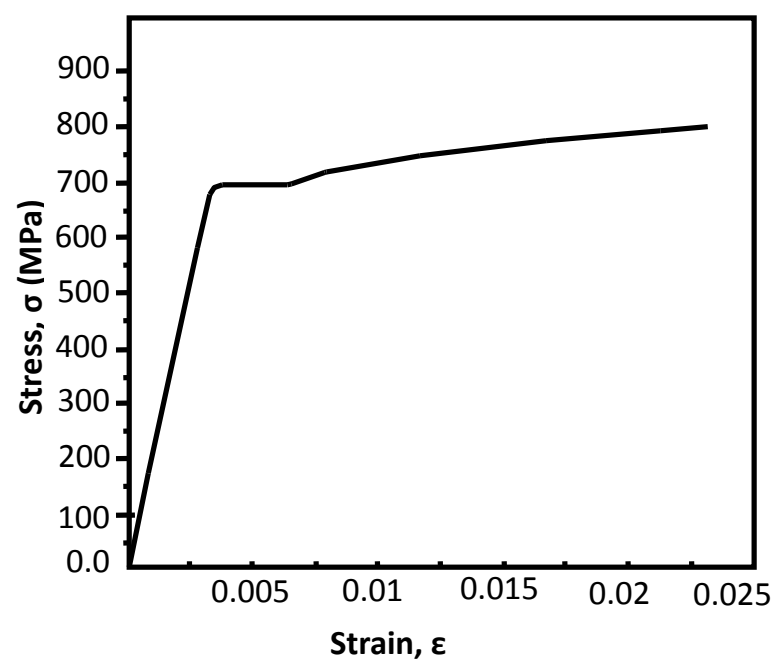

a) HY100.

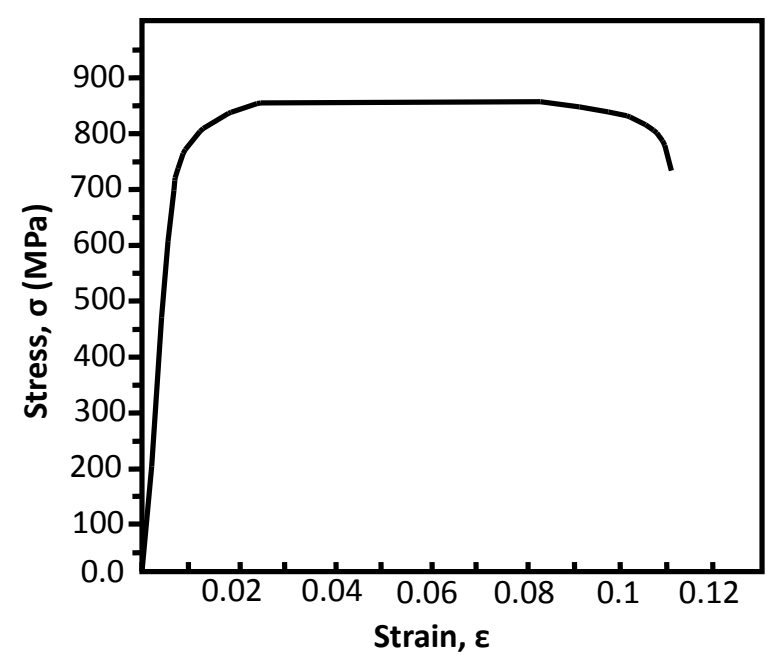

b) Ti-4-V-6.

Fig. 3 The stress strain curve [29].

\section{Optimization Model of Submarine Pressure Hull}

The optimal design problem of elliptical submersible pressure hull under hydrostatic pressure is to minimize the whole weight of the submersible pressure hull. Under constraints on the failure strength and the buckling strength of the hull shell, to reach minimum buoyancy factor, according to the design requirements. There are 
many algorithms and software for implementing the structural optimization are available. In this work, ANSYS software will be used.

The yielding failure strength is based on the von misses yielding criterion. The hull buckling failure strength is based on the buckling load factor must be greater than one. Fig. 4 shows the optimization flow chart for elliptical submersible pressure hull. The optimization model of the design including the design variables, objective function and design constraints. The optimization design is described as follows:

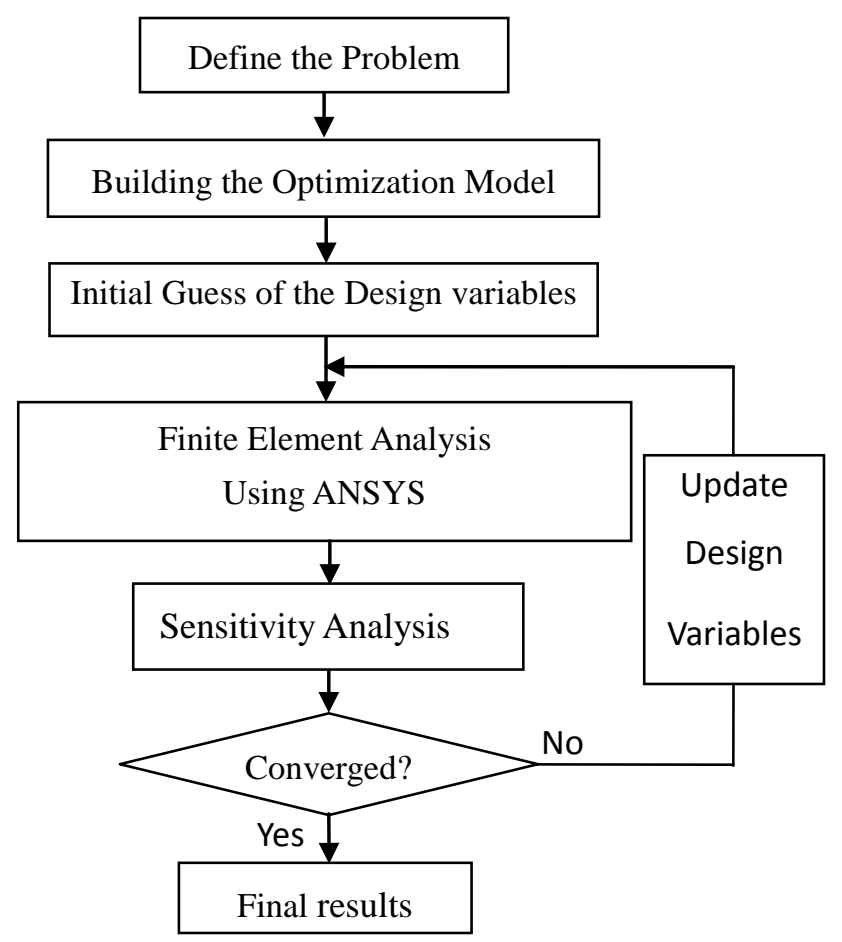

Fig. 4 The optimization flow chart for elliptical submersible pressure hull.

\subsection{Design Variables}

The pre-assigned design parameters are the total length $(L)$ of the submersible pressure hull, the stiffeners offsets in the main part $\left(L_{11}, L_{12}, L_{13}\right.$ and $\left.L_{14}\right)$, the radii of the ellipse of the elliptical submersible pressure hull (the major diameter $\left(D_{\text {major }}\right)$ and the minor diameter $\left(D_{\text {minor }}\right)$ ), the stiffeners dimensions $\left(W_{11}, T_{11}, W_{21}, T_{21}, W_{12}, T_{12}\right.$, $W_{22}$ and $T_{22}$ ), the stiffeners orientation angle $(\theta)$, the operating depth $(H)$, the design load $(P)$ as a function in the operating depth, the material properties, the shell thickness of each part of the submersible pressure hull $\left(T h_{1}, T h_{2}\right.$ and $\left.T h_{3}\right)$.

\subsection{Objective Function}

Buoyancy factor is used to compensate loss of weight due to immersion in water. Buoyancy is the upward force that keeps things afloat. The net upward buoyancy force equals to the amount of the weight of fluid displaced by the body volume. This force will make objects lighter when it immerses in fluid. The common basis for evaluating the structural efficiencies of the various hulls is the buoyancy factor, defined as the hull weight to displaced water weight ratio. It reflects the submersible pressure hull design 
of economical and structural efficiencies of the various hulls. The objective function is to minimize the buoyancy factor and is stated as follows:

$$
\mathrm{F}(\mathrm{X}) \text { : Minimize } B . F=\frac{\text { Total hull weight }}{\text { The weig ht of fluid displaced by the body volume }}
$$

\subsection{Design Constraints}

The constraining equations can be classified into two groups. Behavior constraints, that control the failure modes and side constraints that specify the permissible range of design variables to specify spatial and human requirements. Such constraints are presented as follows.

\subsubsection{Behavior Constraints}

In order to ensure the structural stability, the failure and strength constraints imposed on the elliptical submersible pressure hull, must be satisfied. In this paper, several failure and strength criteria are used as behavior constraints.

Material Strength Constraint: In order to avoid materials yielding in the shell and stiffeners, the stress of the shell and stiffeners is considered to be less than its material yielding strength, respectively. Hence, the strength inequality constraint on the shell and in the stiffeners can be expressed as:

$$
\text { g1: } \frac{\sigma_{\text {shell }}}{\sigma_{s}^{y}}-1 \leq 0
$$

Where, $\sigma_{\text {shell }}$ is the actual stress in the shell, $\sigma_{s}^{y}$ is the yielding strength of shell.

$$
\text { g2: } \frac{\sigma_{r}}{\sigma_{r}^{y}}-1 \leq 0
$$

Where, $\sigma_{r}$ is the actual stress in the stiffener, $\sigma_{r}^{y}$ is the yielding strength of the stiffeners.

Instability Constraint (Buckling Constraint): The minimum critical buckling load $\left(P_{c r}\right)$ must exceed the maximum actual operating loading $(P)$ to ensure the stability of the pressure hull. Therefore, a general instability of elliptical submersible pressure hull is presented as:

$$
\text { g3: } \frac{P}{P_{c r}}-1 \leq 0
$$

\subsubsection{Side Constraints}

In addition, corresponding to the choice of the design variables, the following conditions of the dimensioning belong to the group of side constraints in these investigations:

For the elliptical submersible pressure hull diameters:

$$
D_{i}^{L} \leq D_{i} \leq D_{i}^{U}, i=\max , \min
$$

Where, $D_{i}, D_{i}^{L}$ and $D_{i}^{U}$ represent the $i^{\text {th }}$ elliptical submersible pressure hull diameters, and its upper and lower limits, respectively.

For the length of the main part:

$$
L_{i}^{L} \leq L_{i} \leq L_{i}^{U} \quad i=1,2,3,4
$$

Where, $L_{i}, L_{i}^{U}$ and $L_{i}^{L}$ represent the $i^{\text {th }}$ elliptical submersible pressure hull length of the main part, and its upper and lower limits, respectively. 
For the thickness of the shell:

$$
T h_{i}^{L} \leq T h_{i} \leq T h_{i}^{U}, \quad i=1,2,3
$$

Where, $T h_{i}, T h_{i}^{U}$ and $T h_{i}^{L}$ represent the $i^{t h}$ shell thickness of each part of elliptical submersible pressure hull, and its upper and lower limits, respectively.

For the stiffeners of $\mathrm{T}$ cross-section beam element:

$$
\begin{aligned}
& W_{i 1}^{L} \leq W_{i 1} \leq W_{i 1}^{U} \\
& W_{i 2}^{L} \leq W_{i 2} \leq W_{i 2}^{U} \\
& T_{i 1}^{L} \leq T_{i 1} \leq T_{i 1}^{U} \\
& T_{i 2}^{L} \leq T_{i 2} \leq T_{i 2}^{U}, \mathrm{i}=1,2
\end{aligned}
$$

Where, $W_{i 1}, W_{i 2}, T_{i 1}, T_{i 2}, W_{i 1}^{U}, W_{i 1}^{L}, W_{i 2}^{L}, T_{i 1}^{U}, T_{i 1}^{L}, T_{i 2}^{U}, T_{i 2}^{L}$ represent the $i^{\text {th }}$ stiffener cross section dimensions, and their upper and lower limits, respectively.

For the stiffeners orientation angle $(\theta)$ :

$$
\theta^{L} \leq \theta \leq \theta^{U}
$$

Where, $\theta, \theta^{U}$ and $\theta^{L}$ represent the stiffeners orientation angle, and its upper and lower limits, respectively.

For the operating depth:

$$
H^{L} \leq H \leq H^{U}
$$

Where, $H, H^{U}$ and $H^{L}$ represent the operating depth, and its upper and lower limits, respectively.

\section{Numerical Simulation}

The principal requirement of elliptical submarine submersible pressure hulls is to resist hydrostatic pressure exerted by water, to protect personnel and equipment inboard when submerged. When hydrostatic pressure exceeds a critical value, shell buckling may occur to the pressure hull, and the material yielding exceeds the strength. To understand the mechanical behaviors of elliptical submarine submersible pressure hulls and to avoid these failures, the buckling strength, the yielding failure strength and the maximum deflection are analyzed, using FEA software ANSYS.Fig. 5 shows the finite element model of the hull structure is built in ANSYS. The structure is modeled using SHELL93 (8-node structural shell with six degrees of freedom at each node, Fig. 6a). The BEAM189 (3-node beam element in 3-D with six degrees of freedom occurs at each node, Fig. 6b) is used for stiffeners [40, 41].

Fig. 7 shows the full pressure hull and beam mesh for the global model, which consists of 20808 elements and 55830 nodes. Average element size used in the ANSYS was $0.1 \mathrm{~m}$. To check convergence, the structural model was run with 4 different mesh schemes of element structural model with element sizes $0.3 \mathrm{~m}, 0.2 \mathrm{~m}$, $0.1 \mathrm{~m}$ and $0.05 \mathrm{~m}$. It is seen that the variation in stress values is insignificant, and thus simulation was carried out with $0.1 \mathrm{~m}$ average element size.

The displacement boundary conditions applied in the FE model were as follows:

(1) Symmetry boundary condition in all nodes at $y=0$, and $x=0$ but was not sufficient, since the $\mathrm{z}$-direction due to the fluid flow. Therefore, a $2^{\text {nd }}$ boundary condition was employed.

(2) One single node close to center of gravity of the hull was constrained in the z-direction (longitudinal) i.e. $\mathrm{U}_{\mathrm{z}}=0$. No restriction was imposed in the $\mathrm{y}$-direction 
movement. Submarine motion in the vertical direction (y) was balanced by gravity and buoyancy. These boundary conditions allowed us to capture heave and pitch motion of the submarine in the simulation [42].

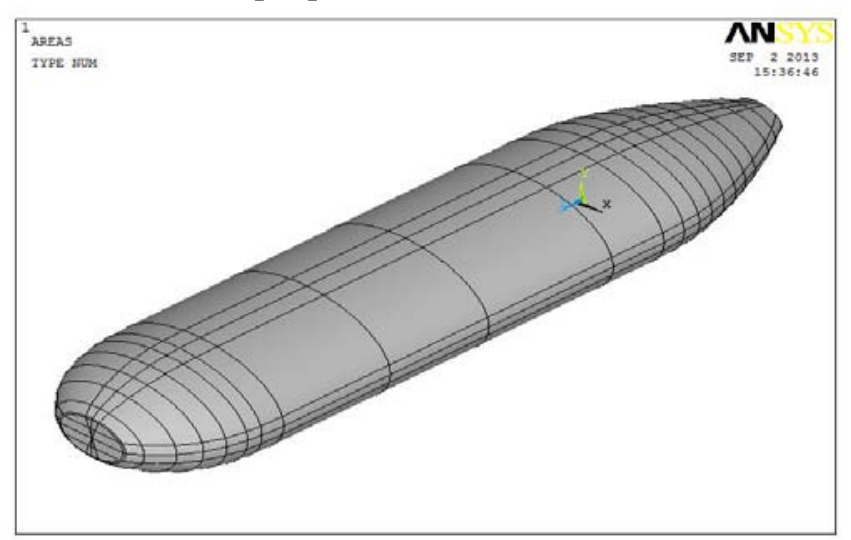

Fig. 5 The finite element model of the hull structure.

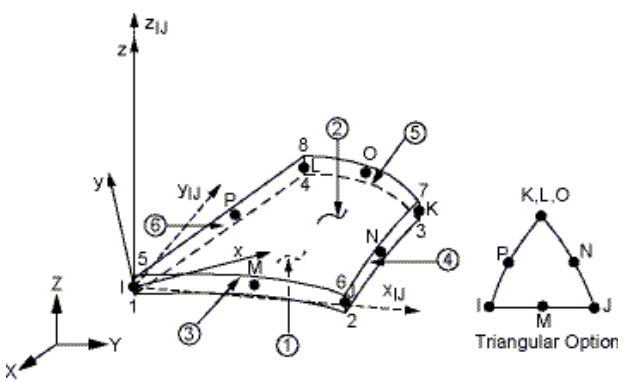

a) SHELL93 Geometry.

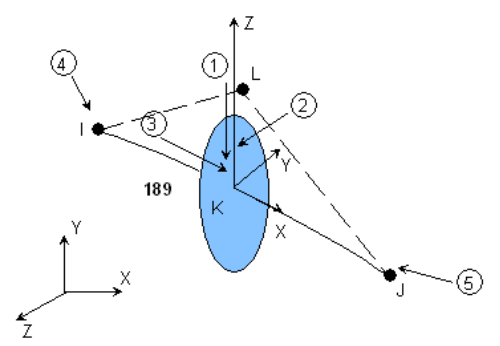

b) BEAM189 Geometry.

Fig. 6 SHELL93and BEAM189 geometry.

\section{Optimal Design Results and Discussion}

The results of the optimization procedures for elliptical deep submersible pressure hull are presented and summarized in Table 2, and Figures 8-13. Table 2 indicates the optimal design point and show that the optimal objective function (buoyancy factor, (B.F)) is 0.6011244 . These results can overcome all structural failures until operating depth $(H)$ of $1772.5 \mathrm{~m}$ in the optimum configuration of the elliptical submersible pressure hull. Additionally, this table also indicates that material yielding, buckling strength factor and maximum permissible deflection are considered to avoid structural failure. Furthermore, a sensitivity analysis is presented to understand thoroughly the effects of the design variables, upon the structural strength of the elliptical submersible pressure hull under hydrostatic pressure. 


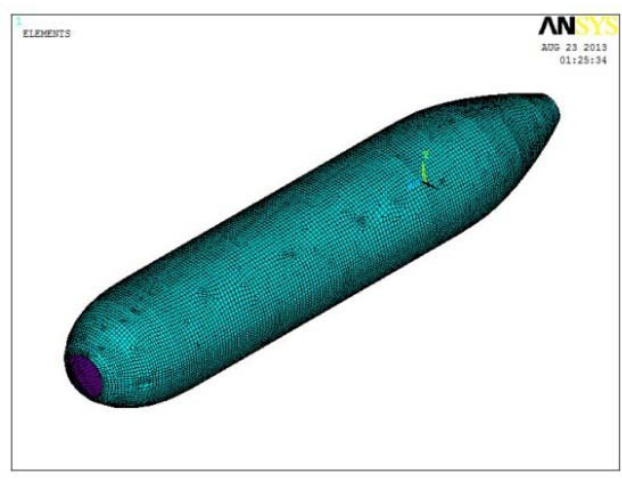

a) Shell element.

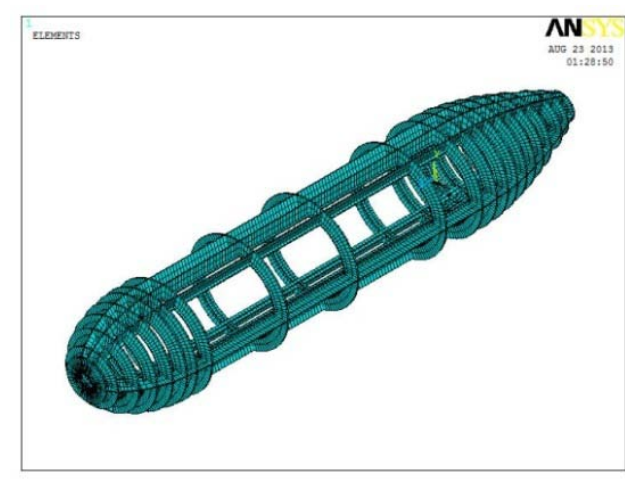

b) Beam element.

Fig. 7 The mesh of the global model.

\subsection{Effect of Buoyancy Factor by Design Variables}

A key factor in determining the payload of elliptical submersible pressure hull is the buoyancy factor. The buoyancy factor is a parameter expressing the efficiency of the structure in terms of its ability to provide for an excess of displacement over that required to support its own weight. 1.0 is seen to be the critical value of the buoyancy factor, where the empty pressure hull is in a condition of neutral buoyancy with zero efficiency with respect to its ability to support other weights.

Fig. 8 shows that, the buoyancy factor (B.F) is directly proportional to each shell thickness $\left(T h_{1}\right)$, stiffener width $\left(W_{11}\right.$ and $\left.W_{21}\right)$. The buoyancy factor is inversely proportional to the major diameter $\left(D_{\text {major }}\right)$ and minor diameter $\left(D_{\text {minor }}\right)$. A larger shell thickness $\left(T h_{1}\right)$ and stiffener width $\left(W_{11}\right.$ and $\left.W_{21}\right)$ all imply a higher buoyancy factor.

A larger major diameter $\left(D_{\text {major }}\right)$ and minor diameter $\left(D_{\text {minor }}\right)$ a lower buoyancy factor, the lowest buoyancy factor corresponds to the strongest ability to increase payload when all design variables are those of the optimal design values.

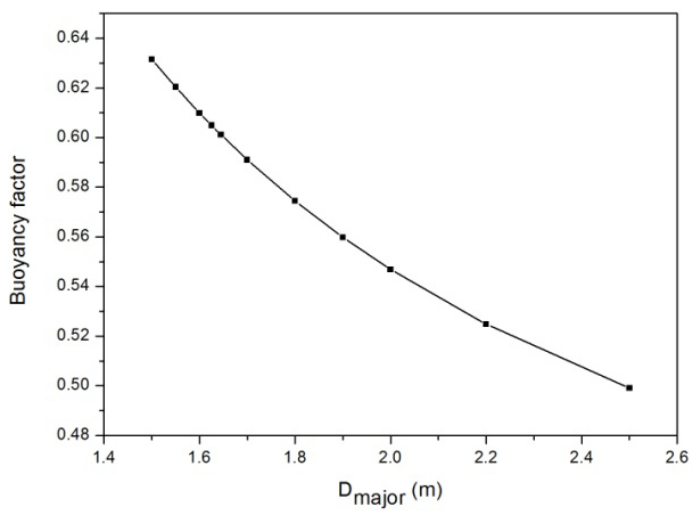

a) $\quad D_{\text {major }}$ upon buoyancy factor.

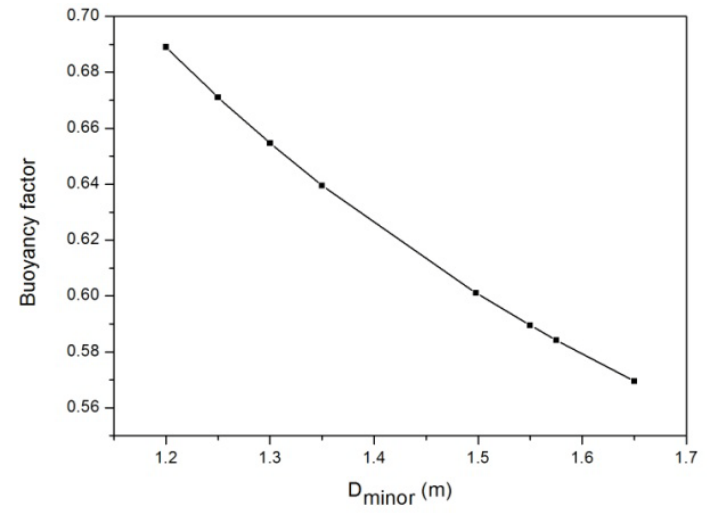

b) $D_{\text {minor }}$ upon buoyancy factor. 


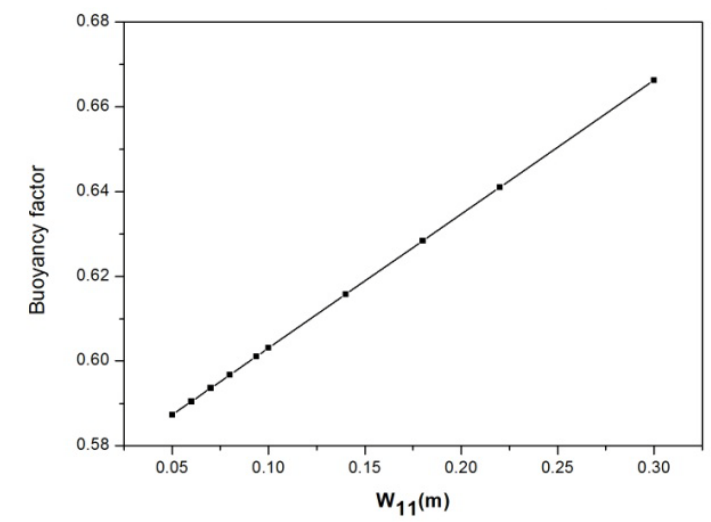

c) $W_{11}$ upon buoyancy factor.

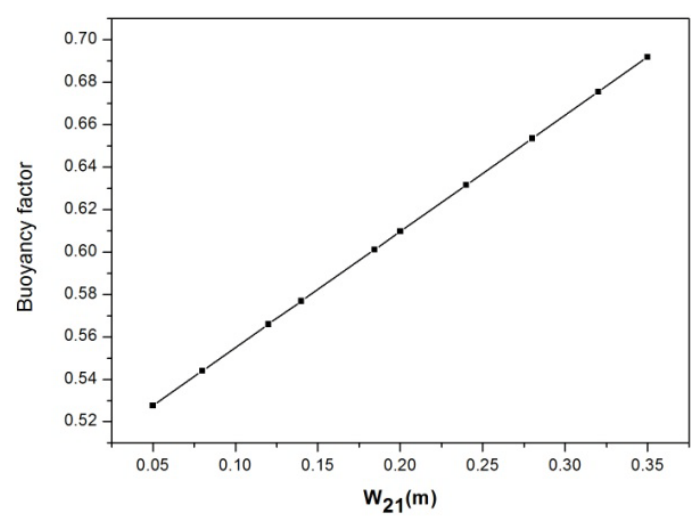

d) $W_{21}$ upon buoyancy factor.

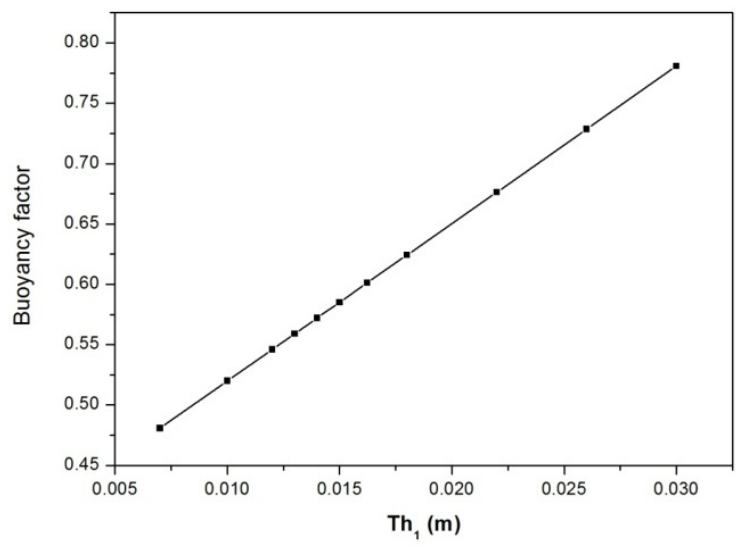

e) $T h_{1}$ upon buoyancy factor.

Fig. 8 The effect of buoyancy factor by design variables.

\subsection{Effect of Deflection Value by Design Variables}

The displacement distributions in both $X$ and $Y$ directions for elliptical submersible pressure hull are shown in Fig. 9. The maximum magnitude of the displacement occurs at centroids regions of the submarine. Fig. 10 showing the effect of operating depth and major diameter upon the maximum deflection value of the elliptical submersible pressure hull. The curve shows that as the operating depth and the major diameter increase the maximum deflection value increase. The influence of major diameter on deflection value is greater than the operating depth.

Fig. 10 shows that, the maximum deflection value is inversely proportional to each shell thickness $\left(T h_{1}\right)$, stiffener width $\left(W_{11}\right.$ and $\left.W_{21}\right)$ and minor diameter $\left(D_{\text {minor }}\right)$. The maximum deflection value is directly proportional to the angle $(\theta)$ until certain value after that the value of the maximum deflection decrease.

Table 2. The results of the optimal design of the elliptical submersible pressure hull.

\begin{tabular}{|l|l|}
\hline Maximum deflection $\left(\delta_{M A X}\right)$ & $0.0145(\mathrm{~m})$ \\
\hline Maximum von Mises stress $\left(\sigma_{M A X}\right)$ & $756(\mathrm{Mpa})$ \\
\hline Buckling strength factor $($ B.S.F $)$ & 22.225 \\
\hline
\end{tabular}


Proceedings of the $\mathbf{1 1}^{\text {th }}$ ICCAE-11 Conference, 19-21 April, 2016

\begin{tabular}{|l|l|}
\hline$S A$ & 2 \\
\hline
\end{tabular}

\begin{tabular}{|l|l|}
\hline$D_{\text {major }}$ & $1.6449(\mathrm{~m})$ \\
\hline$D_{\text {minor }}$ & $1.4979(\mathrm{~m})$ \\
\hline$\theta$ & $19.013(\mathrm{Deg})$ \\
\hline$T_{1}$ & $0.016224(\mathrm{~m})$ \\
\hline$T_{2}$ & $0.019203(\mathrm{~m})$ \\
\hline$T_{3}$ & $0.027479(\mathrm{~m})$ \\
\hline$L_{11}$ & $0.61203(\mathrm{~m})$ \\
\hline$L_{12}$ & $1.4863(\mathrm{~m})$ \\
\hline$L_{13}$ & $1.1804(\mathrm{~m})$ \\
\hline$L_{14}$ & $1.2784(\mathrm{~m})$ \\
\hline$W_{11}$ & $0.093739(\mathrm{~m})$ \\
\hline$W_{21}$ & $0.1843(\mathrm{~m})$ \\
\hline$T_{11}$ & $0.010959(\mathrm{~m})$ \\
\hline$T_{21}$ & $0.018989(\mathrm{~m})$ \\
\hline$W_{12}$ & $0.091317(\mathrm{~m})$ \\
\hline$W_{22}$ & $0.18855(\mathrm{~m})$ \\
\hline$T_{12}$ & $0.01751(\mathrm{~m})$ \\
\hline$T_{22}$ & $0.0122138(\mathrm{~m})$ \\
\hline Operating depth $(\mathrm{H})$ & $1772.5(\mathrm{~m})$ \\
\hline Buoyancy factor $(B . F)$ & 0.6011244 \\
\hline & \\
\hline & \\
\hline
\end{tabular}

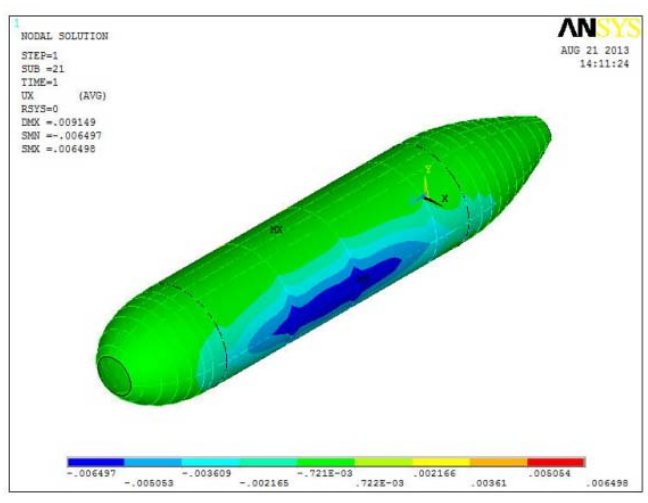

a) Displacement in $X$-direction.

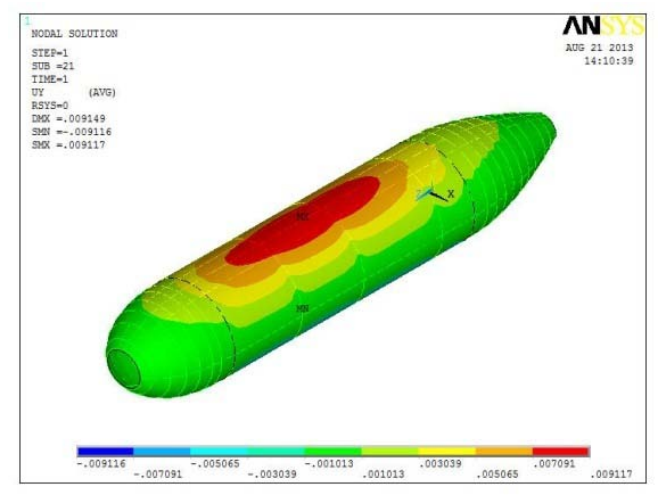

b) Displacement in $Y$-direction. 
Fig. 9 Displacement distribution for elliptical submersible pressure hull.

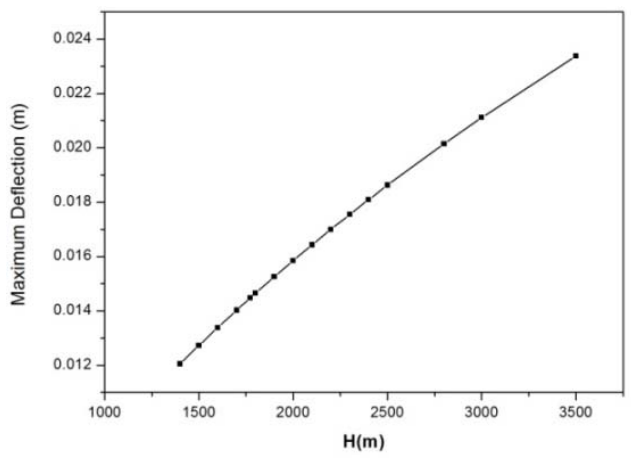

a) $\quad H$ upon Deflection value.

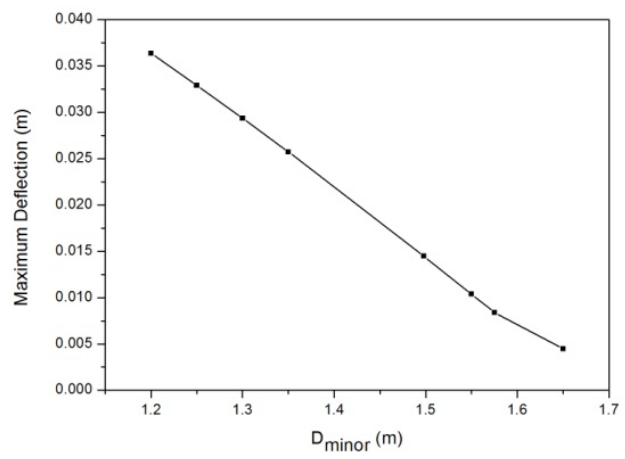

c) $D_{\text {minor }}$ upon Deflection value.

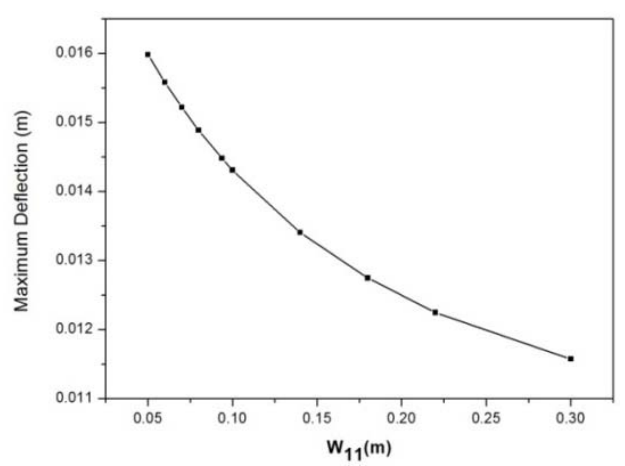

e) $\quad W_{11}$ upon Deflection value.

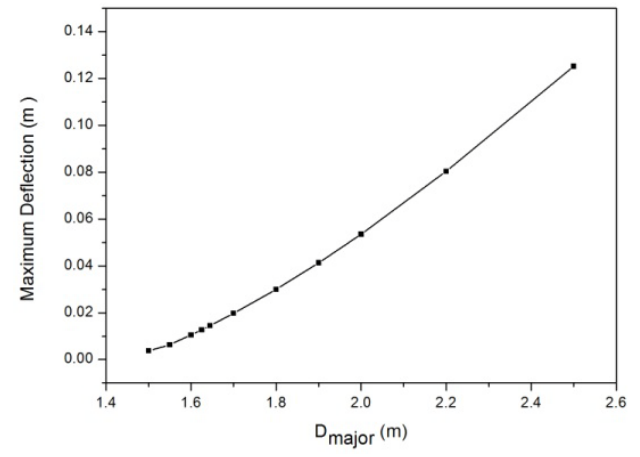

b) $D_{\text {major }}$ upon Deflection value.

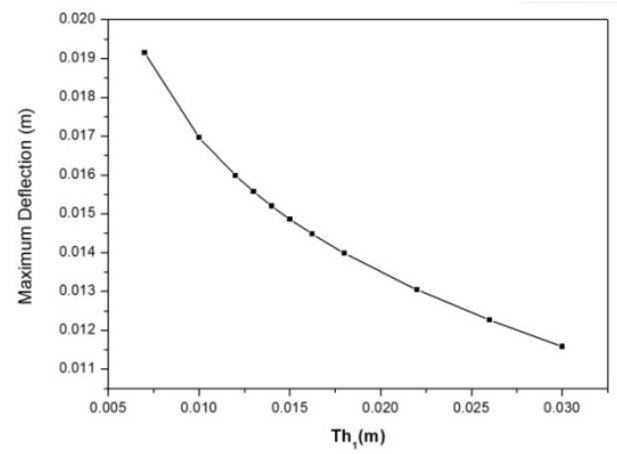

d) $T h_{1}$ upon Deflection value.

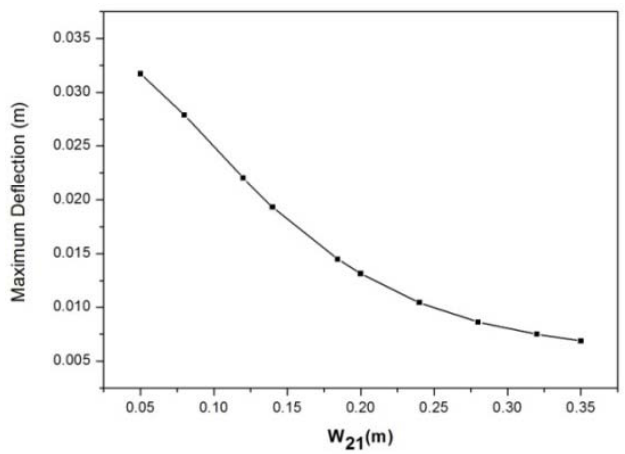

f) $\quad W_{21}$ upon Deflection value.

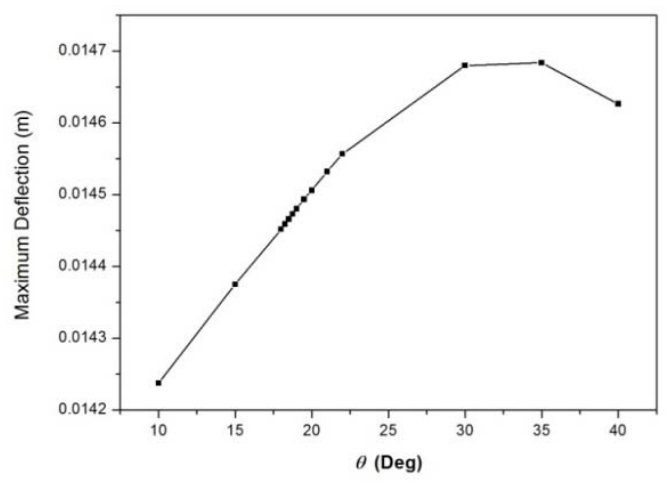

g) $\theta$ upon Deflection value. 
Fig. 10 The effect of maximum deflection by design variables.

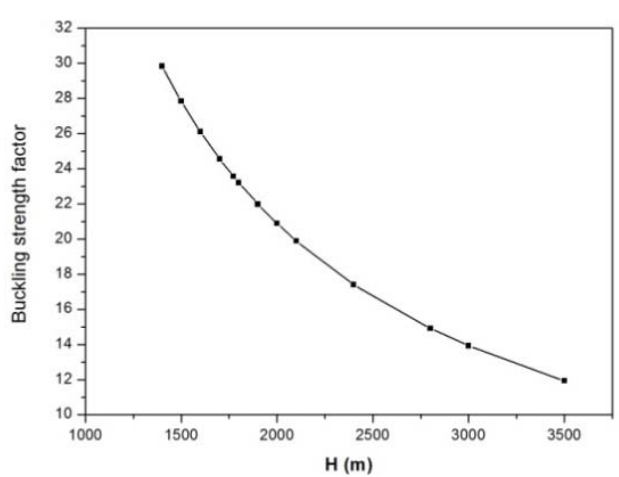

a) $H$ upon buckling strength factor.

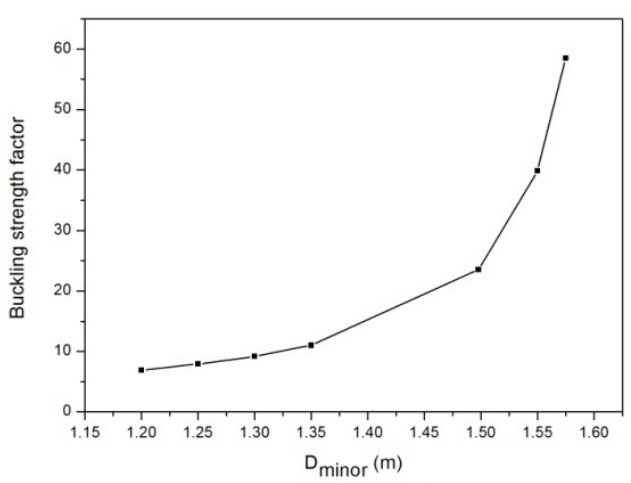

c) $D_{\text {minor }}$ upon buckling strength factor.

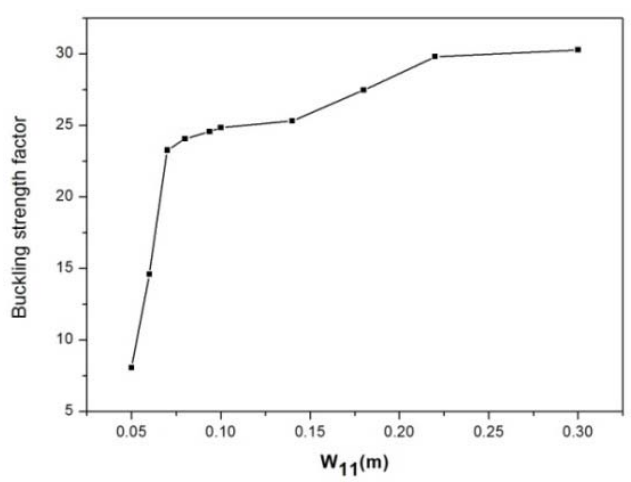

e) $\quad W_{11}$ upon buckling strength factor.

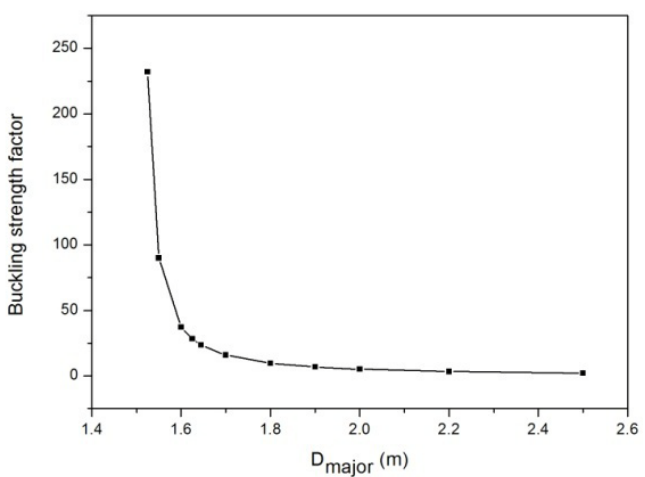

b) $D_{\text {major }}$ upon buckling strength factor.

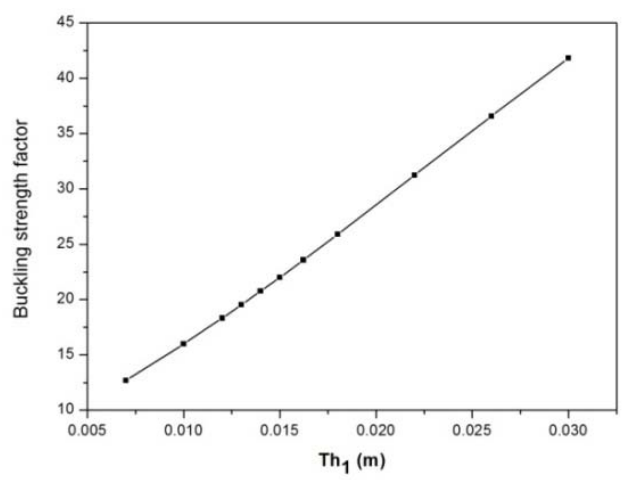

d) $T h_{1}$ upon buckling strength factor.

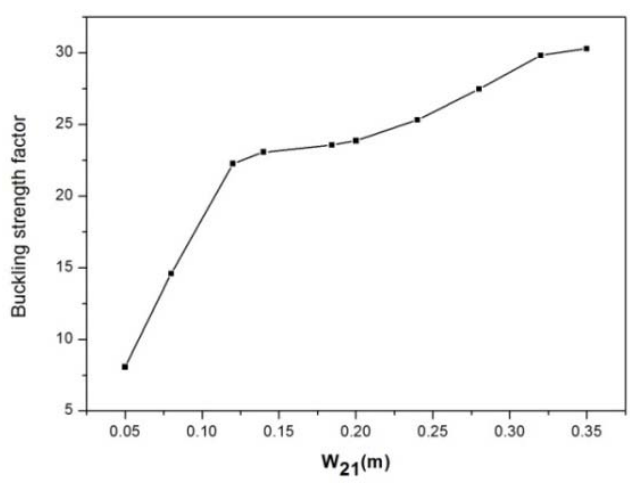

f) $\quad W_{21}$ upon buckling strength factor.

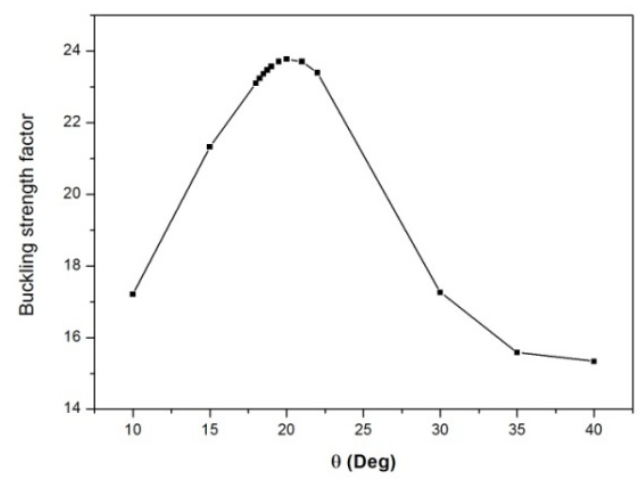

g) $\theta$ upon buckling strength factor.

Fig. 11 The effect of buckling strength factor by design variables. 


\subsection{Effect of Buckling Strength Factor by Design Variables}

Buckling strength factor is the ratio between the critical buckling loads to operating loads and must be greater than 1 to ensure the stability of the pressure hull. Fig. 11a, shows the effect of operating depth upon the buckling strength factor of the elliptical submersible pressure hull. This curve shows that as the operating depth increase the buckling strength factor decreases and the maximum variation occurs when the operating depth greater than $2000 \mathrm{~m}$ and the buckling strength factor decreases rapidly, but the structure still resist the external hydrostatic pressure load without any failure.

Fig. 11b shows the effect of major diameter upon the buckling strength factor. This figure shows that as the major diameter increase the buckling strength factor decreases and the best performance occurs when major diameter in the range from $1.6 \mathrm{~m}$ to $2 \mathrm{~m}$. The maximum variation occurs when the major diameter in the range from 1.525 to $1.6 \mathrm{~m}$ which the buckling strength factor decrease rapidly from 232 to 37 , respectively. The minimum variation occurs when the major diameter in the range from $2 \mathrm{~m}$ to $2.5 \mathrm{~m}$ and the buckling strength factor decrease but the structure still resist the external hydrostatic pressure load without any failure.

Fig. 11c shows the effect of minor diameter upon the buckling strength factor. It shows that as the minor diameter increase the buckling strength factor increase and the best performance occurs, when the minor diameter nearly equal to the major diameter.

Fig. 11d shows the effect of shell thickness upon the buckling strength factor which is directly proportional to shell thickness. Fig. (12e and f) shows the effect of $W_{11}$ and $W_{22}$ on buckling strength factor, and the two figures has the same trend. Fig. $11 \mathrm{~g}$ shows the effect of $\theta$ upon the buckling strength factor, which indicates that, as $\theta$ increase the buckling strength factor increase, until $\theta$ equal to $20^{\circ}$. After that the buckling strength factor decrease rapidly until $\theta$ equal to $30^{\circ}$, and the minimum variation occurs in the range when $\theta$ from $30^{\circ}$ to $40^{\circ}$.

\subsection{Effect of Stress by Design Variables}

Fig. 12 shows the von Mises stress distribution for elliptical submersible pressure hull. Fig. 13a shows the effect of operating depth upon the maximum von Mises stress of the elliptical submersible pressure hull. The curve reveals that, the maximum von Mises stress is directly proportional to operating depth. Fig. 13b shows the effect of major diameter upon the maximum von Mises stress. When the major diameter increases the maximum von Mises stress is nearly constant. After that the maximum von Mises stress increase linear as major diameter increase. The best performance occurs when the major diameter in the range from $1.5 \mathrm{~m}$ to $1.644 \mathrm{~m}$. Fig. 13c reveals the effect of minor diameter upon the maximum von Mises stress value. As the minor diameter increase the maximum von Mises stress decrease, until the minor diameter equal to $1.49 \mathrm{~m}$. After that the von Mises stress approximately remains constant. Fig. 13d shows the effect of shell thickness upon the maximum von Mises stress value, is inversely proportional to shell thickness until the shell thickness equal to $0.016 \mathrm{~m}$, after that as the shell thickness increase the maximum von Mises stress remains constant. 
Fig. 13e shows the effect of $W_{11}$ on maximum von Mises stress value. The figure reveals that, as $W_{11}$ increase the maximum von Mises stress value decrease until $W_{11}$ equal to $0.0937 \mathrm{~m}$. After that maximum von Mises stress value increase as $W_{11}$ increase. Fig. $13 \mathrm{f}$ shows the effect of $W_{21}$ on maximum von Mises stress value. The figure reveals that as $W_{21}$ increase the maximum von Mises stress value increase rapidly, until $W_{21}$ equal to $0.3 \mathrm{~m}$.After that maximum von Mises stress value increase as $W_{21}$ increase. Fig. $13 g$ shows the effect of $\theta$ upon the maximum von Mises stress value. The figure indicate that, as $\theta$ increase the maximum von Mises stress value increase, until $\theta$ equal to $19^{\circ}$. After that the maximum von Mises stress value is remain constant until $\theta$ equal to $22^{\circ}$. After that, the maximum von Mises stress value increases as $\theta$ increase.

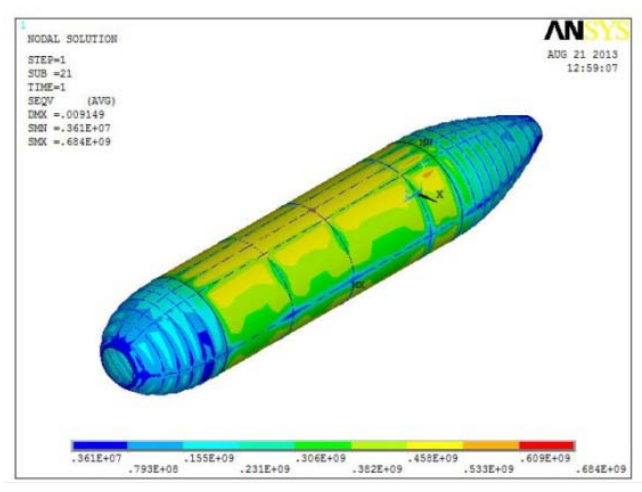

a) Shell elements.

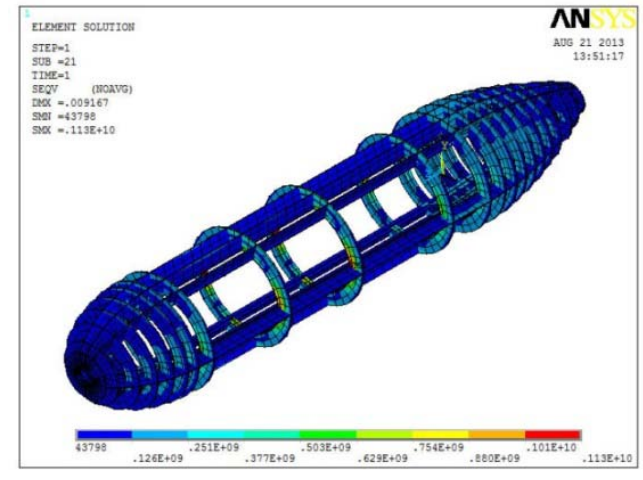

b) Beam elements.

Fig. 12 von Mises stress distribution for elliptical submersible pressure hull.

\section{Conclusions}

This paper presented the optimum design of elliptical submersible pressure hull under hydrostatic pressure to minimize the buoyancy factor of the pressure hull. A sensitivity analysis was performed to study the effects of the design variables on the optimal structural strength design. Constraints were imposed on material yielding failure strengths, permissible deflection and buckling strengths. This study yields the following observations.

The minimum buoyancy factor provides a valuable reference for the submarine pressure hull design, so as to increase the payload and the performance with respect to controlling the submarine.

The failure governed by the maximum von Mises stresses and the optimum point is determined by material failure, which the buckling load is larger than the material failure. So that the current results suggest that the static material failure should be considered in the design of elliptical submersible pressure hull under hydrostatic pressure.

The Design variables ( $D_{\text {major }}, D_{\text {minor }}$ and $T h_{1}$ ) heavily influence upon buoyancy factor, the other design variable ( $W_{11}$ and $W_{21}$ ) have a little influences upon buoyancy factor. The Design variables ( $H$ and $D_{\text {major }}$ ) profoundly influence upon maximum deflection value, which increase as these design variable increase. The other design variable ( $D_{\text {minor }}, T h_{1}, W_{11}$ and $\left.W_{21}\right)$ decrease the maximum deflection value as these 
variable increase. Also the maximum deflection value is directly proportional to the angle $(\theta)$ until certain value after that the value of the maximum deflection decrease. The Design variables $\left(H, D_{\text {major }}, D_{\text {minor }}\right.$ and $\left.T h_{1}\right)$ heavily influence upon maximum von Mises stress. The Design variables $(\theta)$ have a little influences, the other design variable $\left(W_{11}\right.$, and $W_{21}$ ) have a moderate influences upon maximum von Mises stress.

The material yielding must be firstly considered on the optimum design of elliptical submersible pressure hull under hydrostatic pressure.

The results can serve as a valuable reference for designers of underwater vehicles. Future studies should consider the effects of the fluid structure interaction, and the problem of impact due to underwater impulsive load on the pressure hull.

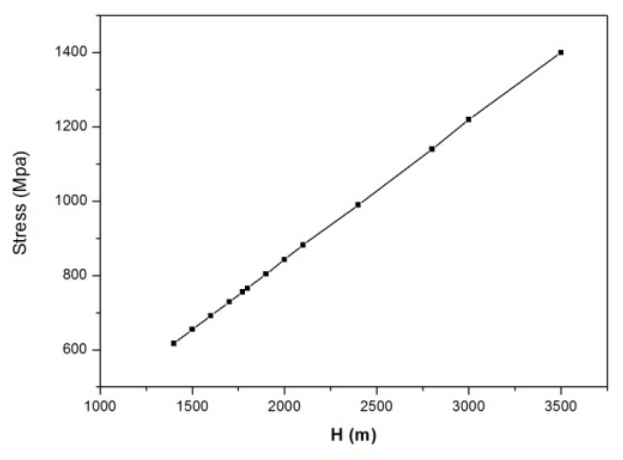

a) $\quad H$ upon stress value.

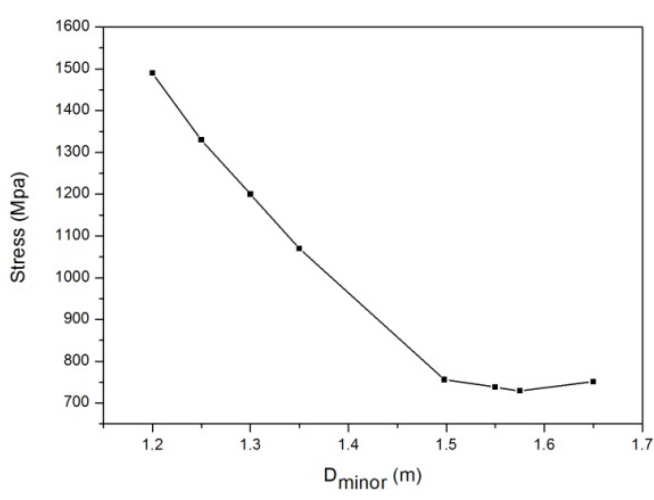

c) $D_{\text {minor }}$ upon stress value.

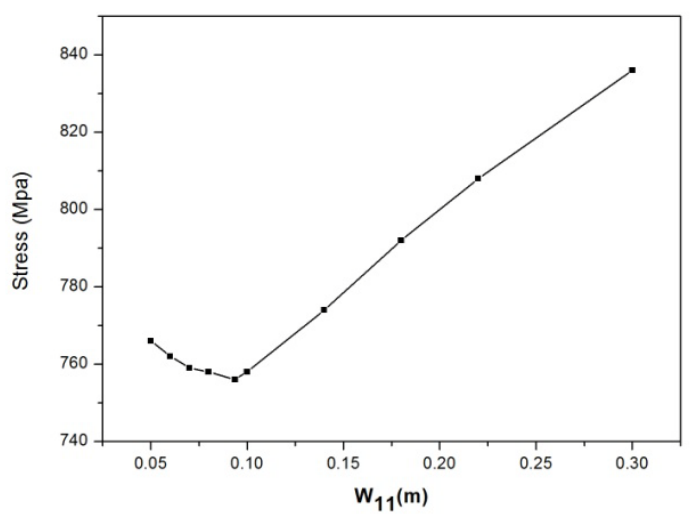

e) $W_{11}$ upon stress value.

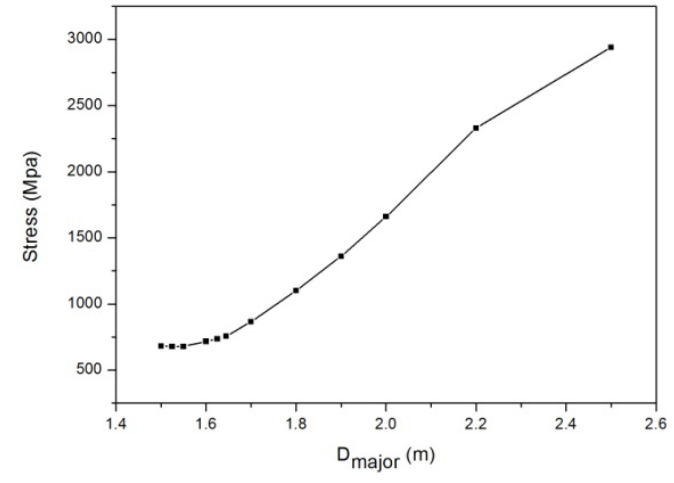

b) $\quad D_{\text {major }}$ upon stress value.

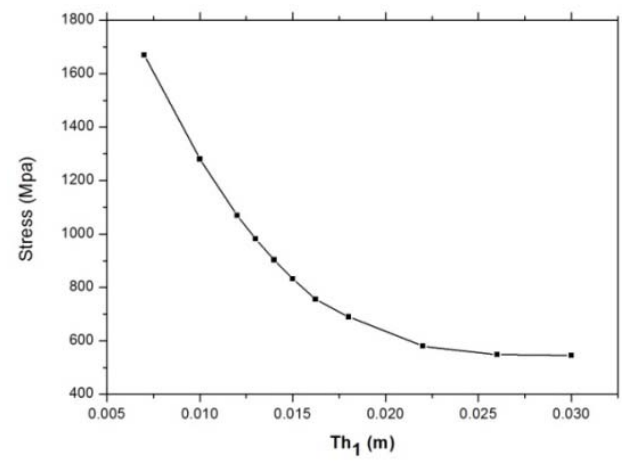

d) Th1 upon stress value.

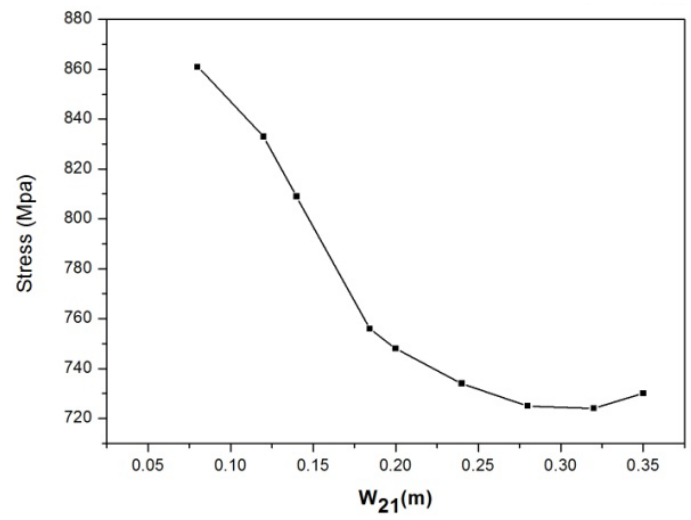

f) $\quad W_{21}$ upon stress value. 


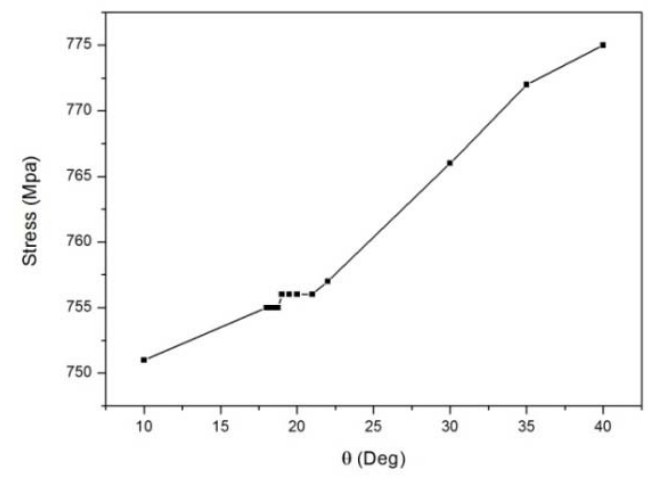

g) $\theta$ upon stress value.

Fig. 13 The effect of maximum von Mises stress by design variables.

\section{References}

[1] J.R. MacKay, F. Keulen, Partial Safety Factor Approach to the Design of Submarine Pressure Hulls Using Nonlinear Finite Element Analysis, Finite Elements in Analysis and Design, 65 (2013) 1-16.

[2] T. Reynolds, O. Lomacky, M. Krenzke, Design and Analysis of Small Submersible Pressure Hulls Computers \& Structures, 3 (1973) 1125-1143.

[3] C.C. Lian, C.C. Liao, C.M. Lu, The Study of Minimum-Weight Optimal Design for Submarine Pressure Hull, Institute of Technology, Chung Cheng, 1989.

[4] C.T.F. Ross, A conceptual Design of an Underwater Vehicle, Ocean Engineering, 33 (2006) 2087-2104.

[5] D. Mills, Submarine Design and Development, Conway Maritime, London, 1984.

[6] C.C. Liang, H.W. Chen, C.Y. Jen, Optimum Design of Filament-wound Multilayer Sandwich Submersible Pressure Hulls, Ocean Engineering, 30 (2003) 1941-1967.

[7] C.C. Liang, C.Y. Hsu, H.R. Tssi, Minimum Weight Design of Submersible Pressure Hull Under Hydrostatic Pressure, Compurers and Strucrtures, 63 (1997) 187-201.

[8] G. Pan, J. Lu, K. Shen, J. Ke, Optimization of Composite Cylindrical Shell Subjected to Hydrostatic Pressure, ICIRA, LNAI 9244 (2015) 81-90.

[9] K. Alam, TapabrataRay, S. G.Anavatti, Design and Construction of an Autonomous Underwater Vehicle, Neurocomputing, 142 (2014) 16-29.

[10] B. Pan, W. Cui, Structural Optimization for a Spherical Pressure Hull of a Deep Manned Submersible Based on an Appropriate Design Standard, Oceanic Engineering, 37 (2012) 564-571.

[11] E. Fathallah, H. Qi, L. Tong, M. Helal, Design Optimization of Composite Elliptical Deep-Submersible Pressure Hull for Minimizing the Buoyancy Factor, Advances in Mechanical Engineering, 2014 (2014).

[12] E. Fathallah, H. Qi, L. Tong, M. Helal, Design optimization of lay-up and composite material system to achieve minimum buoyancy factor for composite elliptical submersible pressure hull, Composite Structures, 121 (2015) 16-26.

[13] E. Fathallah, H. Qi, L. Tong, M. Helal, Multi-Objective Optimization of Composite Elliptical Submersible Pressure Hull for Minimize the Buoyancy Factor and Maximize Buckling Load Capacity, Applied Mechanics and Materials, 578 (2014) 75-82.

[14] A.D. Panteleev, Optimal Design of Minimum Weight Sandwich Plates and Shallow Shells, Applied Mechanics, 20 (1984) 103-107.

[15] C. Garland, Design and Fabrication of Deep-diving Submersible Pressure Hulls, SNAME 
Transactions 76, 1968.

[16] A. Alvarez, V. Bertram, L. Gualdesi, Hull Hydrodynamic Optimization of Autonomous Underwater Vehicles Operating at Snorkeling Depth, Ocean Engineering, 36 (2009) 105-112.

[17] H. Cui, O. Turan, P. Sayer, Learning-based Ship Design Optimization Approach, Computer-Aided Design, 44 (2012) 186-195.

[18] S.S. Ahn, M. Ruzzene, Optimal Design of Cylindrical Shells for Enhanced Buckling Stability:Application to Supercavitating Underwater Vehicles, Finite Elements in Analysis and Design, 42 (2006) 967-976.

[19] T. Tokugawa, Model Experiments on the Elastic Stability of Closed and Cross Stiffened Circular Cylinders Under Uniform External Pressure, in: World Eng, Congr, Tokyo, 1929, pp. 249-279.

[20] M. Bagheri, A.A. Jafari, M. Sadeghifar, Multi-objective Optimization of Ring Stiffened Cylindrical Shells Using a Genetic Algorithm, Journal of Sound and Vibration, 330 (2011) 374-384.

[21] H.K. Jeong, P. Henry, Optimal Design of Deep Sea Pressure Hulls using CAE Tools, Computational Structural, 25 (2012) 477-485.

[22] C.Y. Jen, Coupled Acoustic Structural Response of Optimized ring Stiffened Hull for Scaled down Submerged Vehicle Subject to Underwater Explosion, Theoretical and Applied Fracture Mechanics, 52 (2009) 96-110.

[23] C.Y. Jen, W.H. Lai, Transient Response of Multiple Intersecting Spheres of Deep-Submerged Pressure Hull Subjected to Underwater Explosion, Theoretical and Applied Fracture Mechanics, 48 (2007) 112-126.

[24] C.T.F. Ross, A novel Submarine Pressure Hull Design., Journal of Ship Research, 31 (1987) 186-188.

[25] C.T.F. Ross, A.P.F. Little, The Buckling of a Corrugated Carbon Fibre Cylinder Under External Hydrostatic Pressure, Ocean Engineering 28 (2001) 1247-1264.

[26] C.T.F. Ross, D. Popken, Buckling of Tube-Stiffened Prolate Domes Under External Water Pressure, Thin-Walled Structures, 22 (1995) 159-179.

[27] Harris, F. L, Private Communication, (1977).

[28] C.T.F. Ross, Pressure Vessels External Pressure Technology, Second edition ed., British Library, 2011.

[29] W. Li, X.Z. Ping, Z. Tao, L.T. Guang, Optimum Design of Spherical Deep-submerged Pressure Hull, Journal of Ship Mechanics, 14 (2010) 509-515.

[30] C.J. Moon, I.H. Kim, B.H. Choi, J.H. Kweon, J.H. Choi, Buckling of Filament-wound Composite Cylinders Subjected to Hydrostatic Pressure For Underwater Vehicle Applications, Composite Structures, 92 (2010) 2241-2251.

[31] K.Y. Maalawi, Use of Material Grading for Enhanced Buckling Design of Thin-Walled Composite Rings/Long Cylinders Under External Pressure, Composite Structures, 93 (2011) 351-359.

[32] G.C. Lee, J.H. Kweon, J.H. Choi, Optimization of Composite Sandwich Cylinders for Underwater Vehicle Application, Composite Structures, 96 (2013) 691-697.

[33] P. Radha, K. Rajagopalan, Ultimate Strength of Submarine Pressure Hulls with Failure Governed by Inelastic Buckling, Thin-Walled Structures, 44 (2006) 309-313.

[34] C.C. Liang, W.H. Lai, C.Y. Hsu, Study of the Nonlinear Responses of a Submersible Pressure Hull, International Journal of Pressure Vessels and Piping, 75 (1998) 131-149.

[35] C.T.F. Ross, A conceptual Design of an Underwater Missile Launcher, Ocean Engineering 32 (2005) 85-99.

[36] H. Adeli, K.C. Sarma, Cost Optimization of Structures: Fuzzy Logic, Genetic Algorithms, and Parallel 
Computing, Wiley, 2006.

[37] D. Kalyanmoy, Optimization for Engineering Design: Algorithms and Examples, PHI Learning Pvt. Ltd, Feb 1, 2004.

[38] J. Arora, Introduction to Optimum Design, Elsevier 2011.

[39] C.C. Liang, S.W. Shiah, C.Y. Jen, H.W. Chen, Optimum Design of Multiple Intersecting Spheres Deep-submerged Pressure Hull, Ocean Engineering, 31 (2004) 177-199.

[40] A. Inc, ANSYS Theory Reference Release 14.5, October ed., 2012.

[41] G.I. M. Erdogan, The Finite Element Method and Applications in Engineering Using ANSYS, Springer, New York, 2006.

[42] S. Ma, H. Mahfuz, Finite Element Simulation of Composite Ship Structures with Fluid Structure Interaction, Ocean Engineering, 52 (2012) 52-59. 